\title{
Nanoscaled ceramic powders produced by laser ablation
}

\author{
X.C. Yang ${ }^{\mathrm{a}, *}$, W. Riehemann ${ }^{\mathrm{b}}$, M. Dubiel ${ }^{\mathrm{a}}, \mathrm{H}$. Hofmeister $^{\mathrm{c}}$ \\ a Department of Physics, Friedemann-Bach-Platz 6, Martin Luther University of Halle-wittenberg, D-06108 Halle, Germany \\ ${ }^{\mathrm{b}}$ Institut für Werkstoffkunde und Werkstofftechnik, Technische Universität Clausthal, Agricolastrasse 6, 38678 Clausthal-Zellerfeld, Germany \\ ${ }^{\mathrm{c}}$ Max Planck Institute of Microstructure Physics, Weinberg 2, D-06120 Halle, Germany
}

Received 22 October 2001; accepted 17 June 2002

\begin{abstract}
Copper oxide, silicon carbide and alumina-zirconia nanopowders have been produced by laser ablation in different atmospheres. Particle morphology, phase transformation and powder composition were investigated by X-ray diffraction, transmission electron microscopy, high resolution electron microscopy, and infrared spectroscopy. Targets used for producing the corresponding nanopowders usually melt, evaporate, decompose and oxidize during laser ablation, which lead to phase transformations and composition changes. A model has been proposed to explain the formation mechanism of nanoparticles, especially the nanoparticles embedded in amorphous matrices. (C) 2002 Elsevier Science B.V. All rights reserved.
\end{abstract}

Keywords: Copper oxide; Silicon carbide; Alumina-zirconia solid solution; Nanopowders; Laser ablation

\section{Introduction}

Nanoparticles, which have an intermediate condition between atoms or molecules and bulk materials, are expected to possess novel electronic, optical, magnetic, transport, photochemical, electrochemical and mechanical properties [1-4]. Thus increasing attention has been given to the fabrication and characterization of nanoparticles during recent decades, various techniques such as physical or chemical vapor condensation [5-8], solgel [9], rapid solidification [10], liquid precursor processes [11], flame processes [12-14] and laser ablation $[15,16]$ have been adapted to synthesize nanoparticles. Numerous studies in nanoparticles deeply increase the understanding of phenomena related to luminescence, catalysis, chemisorption, aerosol, powder metallurgy, ferrofluid etc. Nanoparticles of almost all-inorganic materials can easily be produced by laser ablation because all inorganic materials can be evaporated by high-intensity laser beams and be subsequently condensed into particles. Adjusting the synthesis conditions such as laser parameters, ambient atmospheres and gas flow rates can control particle sizes, morphologies and

\footnotetext{
* Corresponding author

E-mail address: xcyangg@yahoo.com (X.C. Yang).
}

compositions. Especially the particle surfaces can be kept free of contamination of solvents and other residuals, which make the nanoparticles usable in catalysts and gas sensors. Becker [17] generated metallic nanoparticles by laser ablation. In this paper, copper oxide, $\mathrm{SiC}$ and $\mathrm{ZrO}_{2}-\mathrm{Al}_{2} \mathrm{O}_{3}$ systems were chosen based on their wide range of applications. For example, $\mathrm{Cu}_{2} \mathrm{O}$ can be used as heterogeneous catalysts, photocatalyst for water splitting under visible light irradiation, pigments and sensors [18]; $\mathrm{SiC}$ is a good candidate for hightemperature structural ceramics and high-temperature electronic and optoelectronic devices [19,20]; and the $\mathrm{Al}_{2} \mathrm{O}_{3}-\mathrm{ZrO}_{2}$ system can be widely used for oxygen sensors, high-temperature fuel cells, thermal barrier coatings, catalyst support and toughened ceramics $[21,22]$.

\section{Experimental}

In our experiments, some ceramic nanopowders are prepared by laser evaporation of compressed micrometer powders with a $400 \mathrm{~W}$ Nd:YAG-laser (wavelength $=1.06 \mu \mathrm{m}$ ) and subsequent recondensation of the laser-induced vapor in different atmospheres at $9 \times 10^{4} \mathrm{~Pa}$. Nanoparticles generated by gas-phase condensation were collected on a glass fiber filter with an 
average pore size of several micrometer at room temperature using membrane separation technique when the aerosol was pumped out of the evaporation chamber. For the laser ablation, the following parameters were used: laser pulse width $0.5 \mathrm{~ms}$, pulse repetition rate $34 \mathrm{~Hz}$ and laser light pulse power density $5600 \mathrm{~W} \mathrm{~mm}{ }^{-2}$. The experimental set-up is schematically shown in Fig. 1. The laser beam was focussed on the target through a quartz window and made the target material evaporate. In order to ablate the whole surface of the target, the evaporation chamber was mounted on a computer controlled $x-y$ manipulator. Gas was introduced in the evaporation chamber to change the atmosphere and pressure. In addition, it was also used to prevent the powders from depositing on the quartz window. The characteristics of the micrometer powders are shown in Table 1.

$\mathrm{Al}_{2} \mathrm{O}_{3}-\mathrm{ZrO}_{2}$ micropowders containing $28.5 \mathrm{~mol} \%$ $\mathrm{Al}_{2} \mathrm{O}_{3}(\# \mathrm{~A})$ and $31.0 \mathrm{~mol} \% \mathrm{Al}_{2} \mathrm{O}_{3}(\# \mathrm{~B})$ were mixed about $36 \mathrm{~h}$, respectively. $\mathrm{CuO}, \mathrm{SiC}$ and $\mathrm{Al}_{2} \mathrm{O}_{3}-\mathrm{ZrO}_{2}$ micropowders all were compressed into $30 \mathrm{~mm}$ diameter samples with a pressure of $1 \mathrm{MPa}$.

$\mathrm{X}$-ray diffraction (XRD) patterns of these powders were recorded using a Siemens X-ray diffractometer (D5000) with $\mathrm{CuK}_{\alpha}$ radiation at $40 \mathrm{KV}$ and $30 \mathrm{~mA}$. A Phillips CM200 transmission electron microscope (TEM) was used for determining particle morphologies and sizes. Microstructural characterization of nanoparticles was determined by a JEM 4000 EX high resolution TEM (HRTEM). IR spectra were recorded using a Nicolet FTIR-5dx Fourier transform infrared spectroscope.

\section{Results}

\subsection{Copper oxide nanopowders}

Fig. 2(a and b) give the XRD diagrams of copper oxide nanometer powders produced by laser evaporation in air and in argon, respectively. The results show

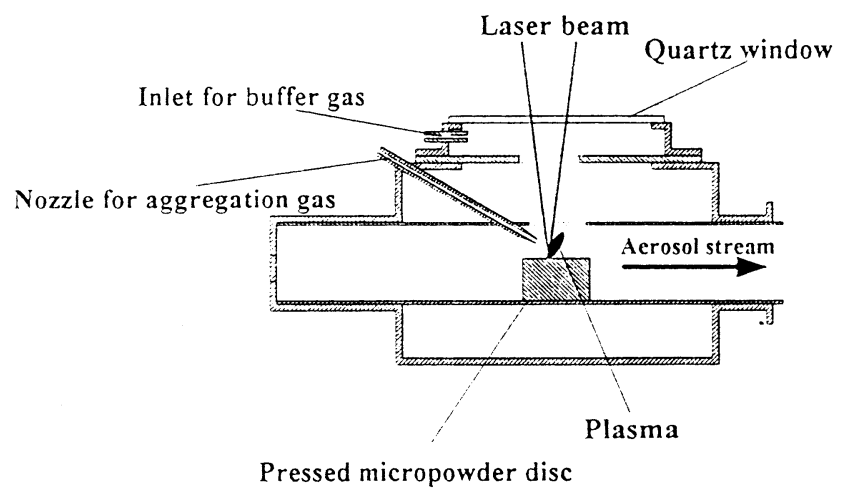

Fig. 1. Schematic diagram of the laser ablation apparatus.
Table 1

Characteristics of the micrometer powders

\begin{tabular}{llll}
\hline Sample & Phase & Purity $(\%)$ & Mean particle size $(\mu \mathrm{m})$ \\
\hline $\mathrm{CuO}$ & Monoclinic & 99.9 & 2.0 \\
$\mathrm{SiC}$ & Alpha & 99.75 & 2.5 \\
$\mathrm{Al}_{2} \mathrm{O}_{3}$ & Alpha & 99.99 & 1.0 \\
$\mathrm{ZrO}_{2}$ & Monoclinic & 99.9 & 1.5 \\
\hline
\end{tabular}

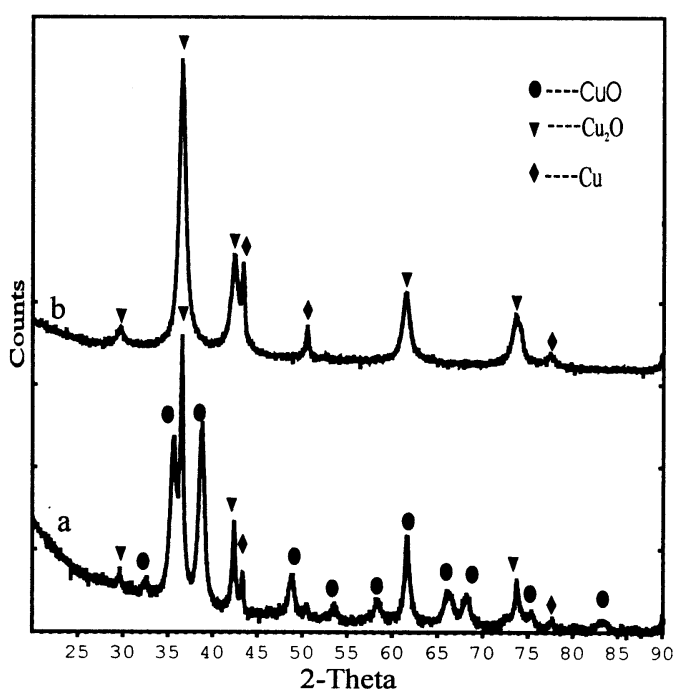

Fig. 2. XRD diagrams of copper oxide nanometer powders produced in air (a) and in argon (b) by laser evaporation.

that copper oxide nanometer powder produced in air consists of $\mathrm{CuO}, \mathrm{Cu}_{2} \mathrm{O}$ and a minor amount of $\mathrm{Cu}$, but only $\mathrm{Cu}$ and $\mathrm{Cu}_{2} \mathrm{O}$ can be found in the nanometer powder produced in argon. Fig. 3(a and b) are TEM photographs of nanopowders produced in air and in argon, respectively. Comparing their morphologies, we found that the powder produced in air consists of nearly spherical particles, and these particles obey a lognormal size distribution with a mean size of about $12 \mathrm{~nm}$ as shown in Fig. 4. The powder produced in argon atmosphere, however, consists of needle-like particles with lengths of about $200 \mathrm{~nm}$ and widths of about $45 \mathrm{~nm}$. To our knowledge, the structure of $\mathrm{Cu}_{2} \mathrm{O}$ nanowires was not reported before.

\subsection{SiC nanopowder}

Fig. 5 gives the XRD diagrams of $\mathrm{SiC}$ micropowder and its nanopowders produced in argon (ASC) and $\mathrm{N}_{2}$ (NSC). It indicates that the $\mathrm{SiC}$ micropowder is $\alpha$-phase and the corresponding nanopowders are $\beta$-phase. A minor amount of crystalline $\mathrm{SiO}_{2}$ was found in ASC.

IR spectra in Fig. 6 show that ASC and NSC have similar absorption peaks: the $\mathrm{Si}-\mathrm{O}-\mathrm{Si}$ bending vibrations around $470 \mathrm{~cm}^{-1}$, the $\mathrm{Si}-\mathrm{O}-\mathrm{Si}$ stretching vibrations around $1100 \mathrm{~cm}^{-1}$, the $\mathrm{Si}-\mathrm{C}$ stretching modes 

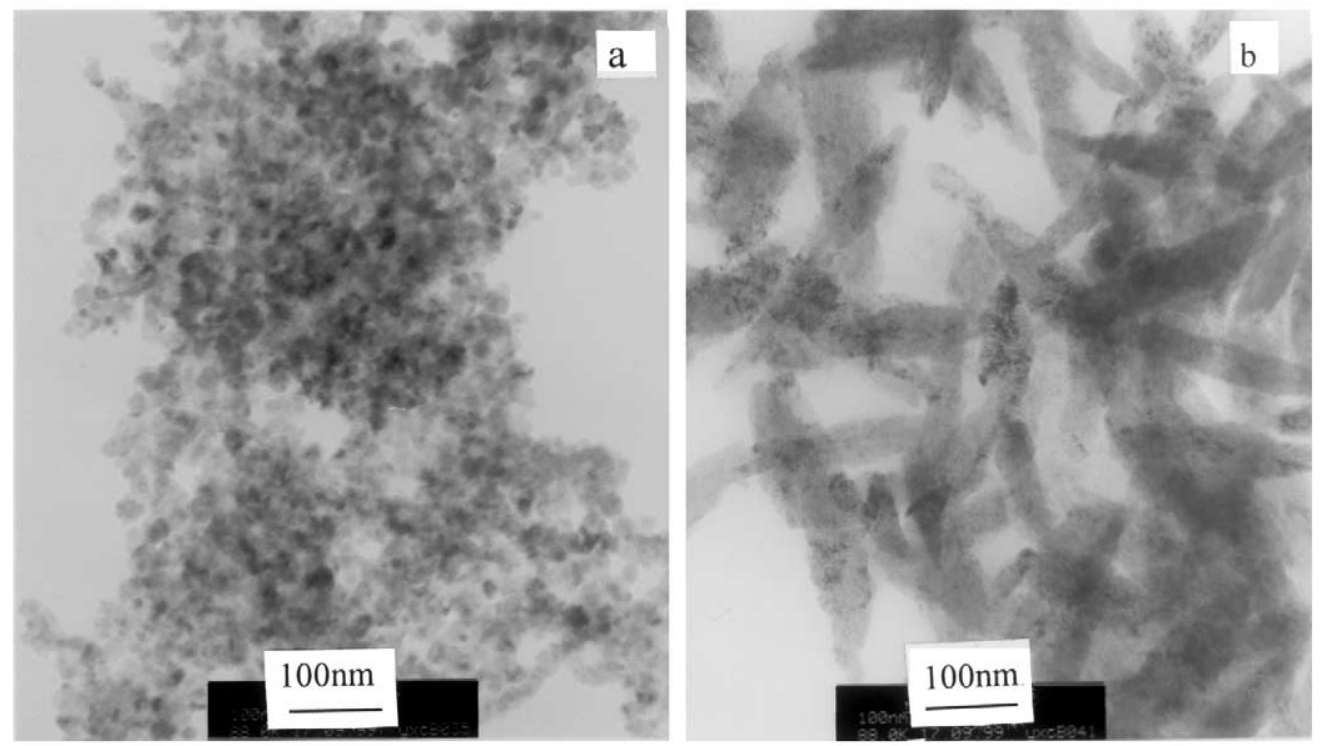

Fig. 3. TEM photographs of copper oxide nanopowders produced in air (a) and in argon (b).

around $870 \mathrm{~cm}^{-1}$, the $\mathrm{O}-\mathrm{H}$ bending vibrations at 1620 $\mathrm{cm}^{-1}$ and the $\mathrm{O}-\mathrm{H}$ stretching vibrations around 3300 $3580 \mathrm{~cm}^{-1}$. The $\mathrm{O}-\mathrm{H}$ vibrations originate from $\mathrm{H}_{2} \mathrm{O}$ adsorbed by $\mathrm{KBr}$-containing samples. The strong absorption around $1100 \mathrm{~cm}^{-1}$ in NSC shows that $\mathrm{SiC}$ was oxidized seriously in $\mathrm{N}_{2}$ because the used $\mathrm{N}_{2}$ contains high levels of oxygen impurity. In NSC a shoulder peak appears at $1200 \mathrm{~cm}^{-1}$ besides $\mathrm{Si}-\mathrm{O}-\mathrm{Si}$ stretching vibration at $1075 \mathrm{~cm}^{-1}$, but in $\mathrm{ASC}$, the $\mathrm{Si}-\mathrm{O}-\mathrm{Si}$ stretching vibration completely splits into a two-peak structure $\left(1063\right.$ and $\left.1202 \mathrm{~cm}^{-1}\right)$. Considering the existence of crystalline $\mathrm{SiO}_{2}$ observed by XRD in ASC, the two-peak structure can be attributed to two different types of $\mathrm{Si}-\mathrm{O}-\mathrm{Si}$ bonds: crystalline $\mathrm{SiO}_{2}$ at $1202 \mathrm{~cm}^{-1}$ and amorphous $\mathrm{SiO}_{2}$ at $1063 \mathrm{~cm}^{-1}$ [23]. Fig. 7 gives the TEM photographs of the $\mathrm{SiC}$ nanopowders produced in $\mathrm{Ar}$ and $\mathrm{N}_{2}$ atmospheres. SiC mean particle sizes in ASC and NSC are 20 and $24 \mathrm{~nm}$, respectively.

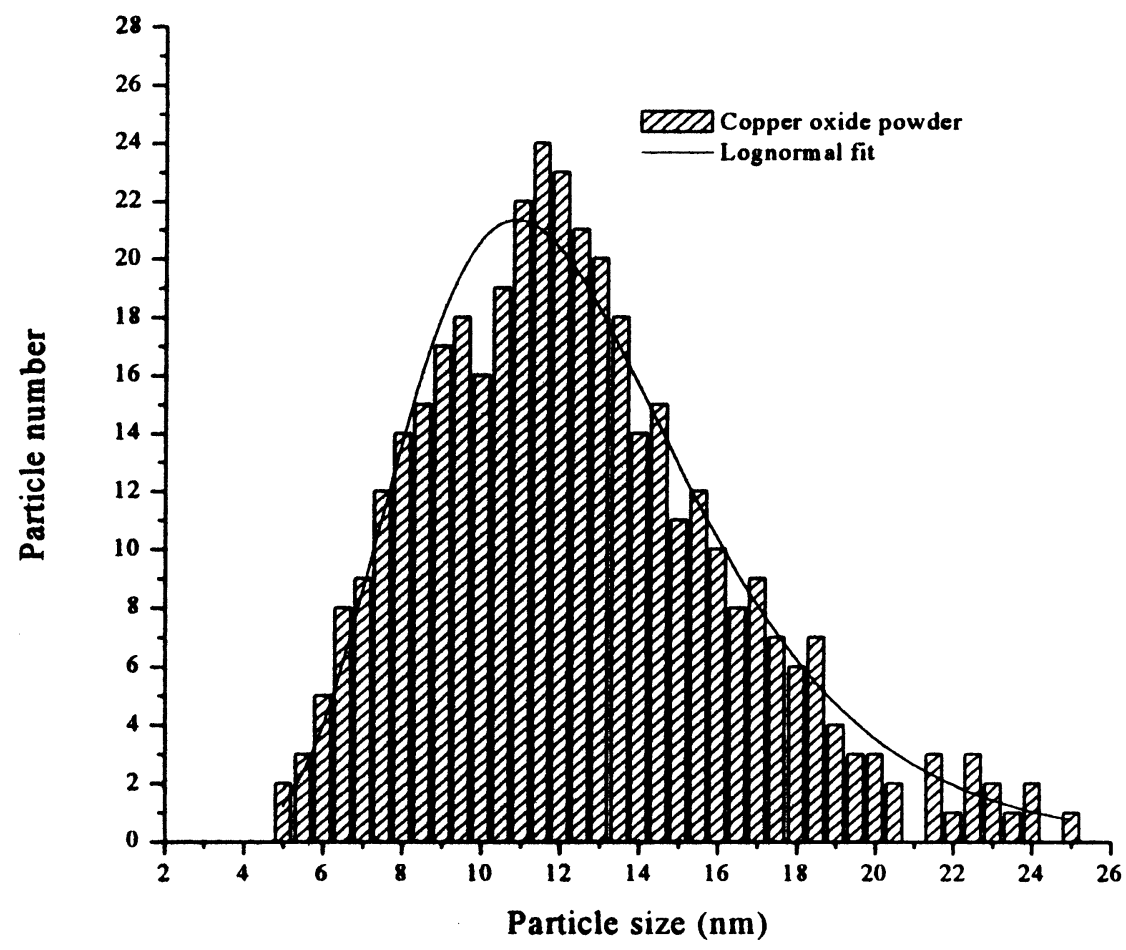

Fig. 4. Particle size distribution of copper oxide nanopowder produced in air atmosphere. 


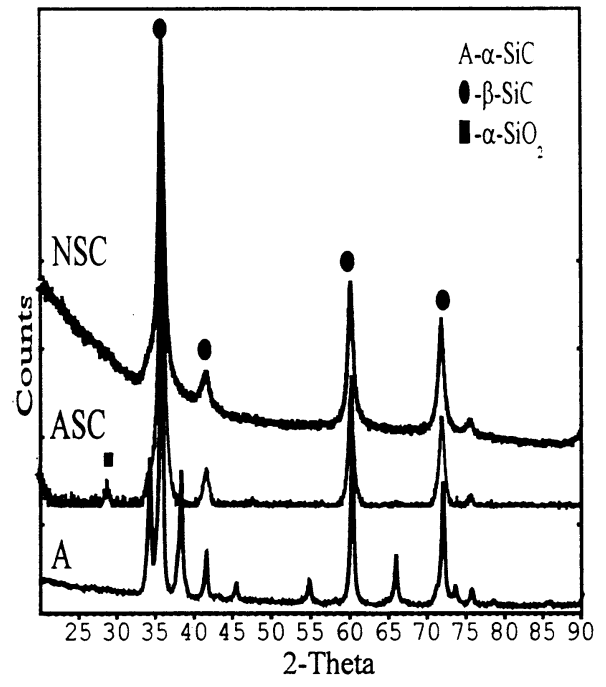

Fig. 5. XRD diagrams of $\mathrm{SiC}$ micropowder and the according nanopowders produced in $\mathrm{Ar}$ and $\mathrm{N}_{2}$.

More amorphous substances can be observed in Fig. 7(b) than in (a), further showing that $\mathrm{SiC}$ was oxidized more seriously in $\mathrm{N}_{2}$ than in Ar.

\subsection{Nanopowders of $\mathrm{Al}_{2} \mathrm{O}_{3}-\mathrm{ZrO}_{2}$ solid solution}

Fig. 8 gives XRD diagrams of samples \#A and \#B. Fig. 9 gives XRD diagrams of NS1 and NS2 that were produced from samples \#A and \#B by laser ablation in air atmosphere, respectively. Fig. 8 shows that samples \#A and \#B both consist of $\mathrm{m}-\mathrm{ZrO}_{2}$ and $\alpha-\mathrm{Al}_{2} \mathrm{O}_{3}$. Fig. 9 shows that NS2 consists of $\mathrm{t}-\mathrm{ZrO}_{2}$ and $\gamma-\mathrm{Al}_{2} \mathrm{O}_{3}$, but no $\mathrm{Al}_{2} \mathrm{O}_{3}$ diffraction peaks exist in NS1. IR spectra in Fig. 10 further demonstrate that no second phase $\mathrm{Al}_{2} \mathrm{O}_{3}$ exists in NS1, but in NS2 exists a second phase $\mathrm{Al}_{2} \mathrm{O}_{3}$ as indicated by a shoulder peak at $840 \mathrm{~cm}^{-1}$ [24]. The absorption peak at $605 \mathrm{~cm}^{-1}$ can be attributed to $\mathrm{ZrO}_{2}$ because it is similar to the IR peak of the $20 \mathrm{~mol}^{\circ} \mathrm{Al}_{2} \mathrm{O}_{3}$ doped $\mathrm{ZrO}_{2}$ nanoparticles reported in Ref. [25]. The absorption peaks at 1573 and $1360 \mathrm{~cm}^{-1}$ can be attributed to $\mathrm{CO}_{2}$ impurities. The $\mathrm{O}-\mathrm{H}$ stretching vibrations around $3470 \mathrm{~cm}^{-1}$ result from $\mathrm{H}_{2} \mathrm{O}$ adsorbed by the $\mathrm{KBr}$-containing samples. The existence of the second phase $\mathrm{Al}_{2} \mathrm{O}_{3}$ in NS2 shows that the $\mathrm{Al}_{2} \mathrm{O}_{3}-\mathrm{ZrO}_{2}$ system has a solid solution limit with increasing $\mathrm{Al}_{2} \mathrm{O}_{3}$ content in the starting samples. In our processing conditions, the solid solution limit is about $28 \mathrm{~mol} \%$ $\mathrm{Al}_{2} \mathrm{O}_{3}$. The solid solution limit of the $\mathrm{Al}_{2} \mathrm{O}_{3}-\mathrm{ZrO}_{2}$ system produced in air is a little smaller than that produced in $\operatorname{Ar}(33 \mathrm{~mol} \%$ ) [26]. This can be explained using the following reaction equations:

$\mathrm{Al}_{2} \mathrm{O}_{3} \stackrel{\mathrm{ZrO}_{2}}{\rightarrow} 2 \mathrm{Al}_{\mathrm{Zr}}^{\prime}+V_{\mathrm{O}}^{*}+3 \mathrm{O}_{\mathrm{O}}^{\times}$

$\mathrm{ZrO}_{2}+x \mathrm{Al}^{3+} \rightarrow \mathrm{Zr}_{(1-x)} \mathrm{Al}_{x} \mathrm{O}_{(2-x / 2)}+x / 4 \mathrm{O}_{2} \uparrow$

It can be seen that oxygen gas in air retards the formation of the solid solution.

In Fig. 9, $\mathrm{ZrO}_{2}$ diffraction peaks can be identified as tetragonal or/and cubic $\mathrm{ZrO}_{2}$ since it is not easy to distinguish between them using XRD due to the severe peak broadening [27]. The solid solution of $\mathrm{Al}_{2} \mathrm{O}_{3}$ in $\mathrm{ZrO}_{2}$ induced $\mathrm{ZrO}_{2}$ lattice distortion and made the according diffraction peaks shift to larger diffraction angles. The crystalline sizes of zirconia in NS1 and NS2 are about 5.1 and $4.2 \mathrm{~nm}$, respectively, and the crystalline size of alumina is about $6.1 \mathrm{~nm}$ as calculated from the broadening of the $t$ (111) and $\gamma$ (440) diffraction peaks by using Scherrer formula [28]:

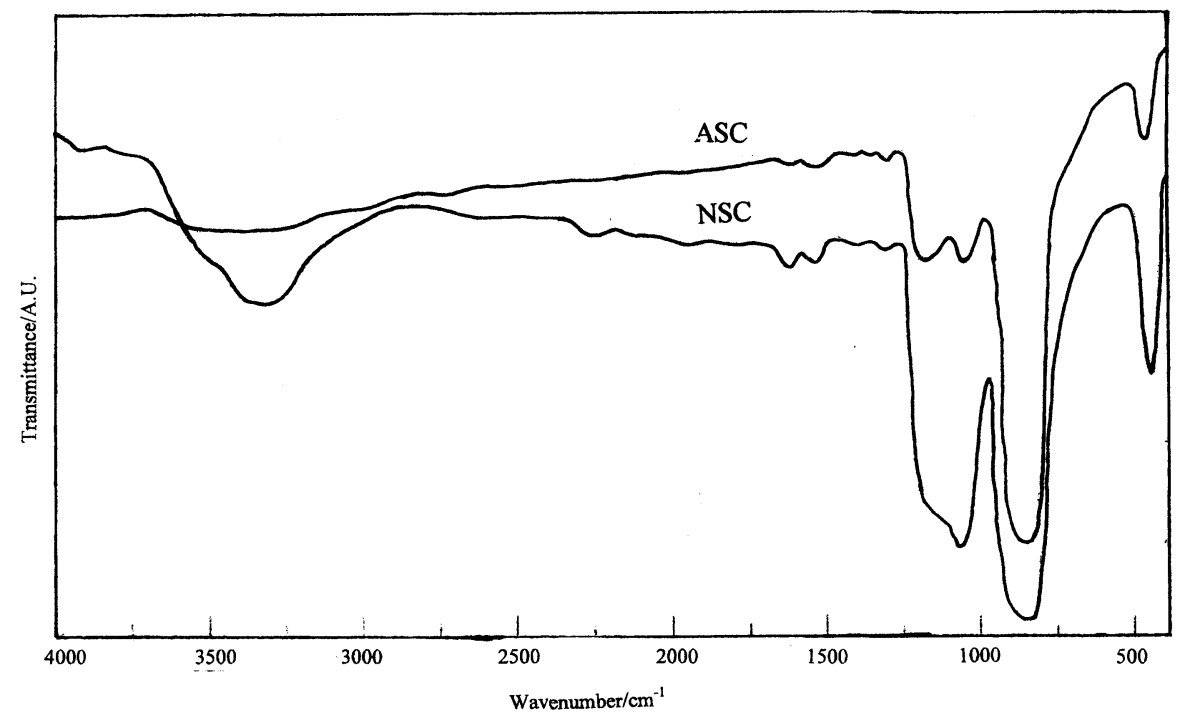

Fig. 6. IR absorption spectra of the nanopowders produced in $\mathrm{Ar}$ and $\mathrm{N}_{2}$. 

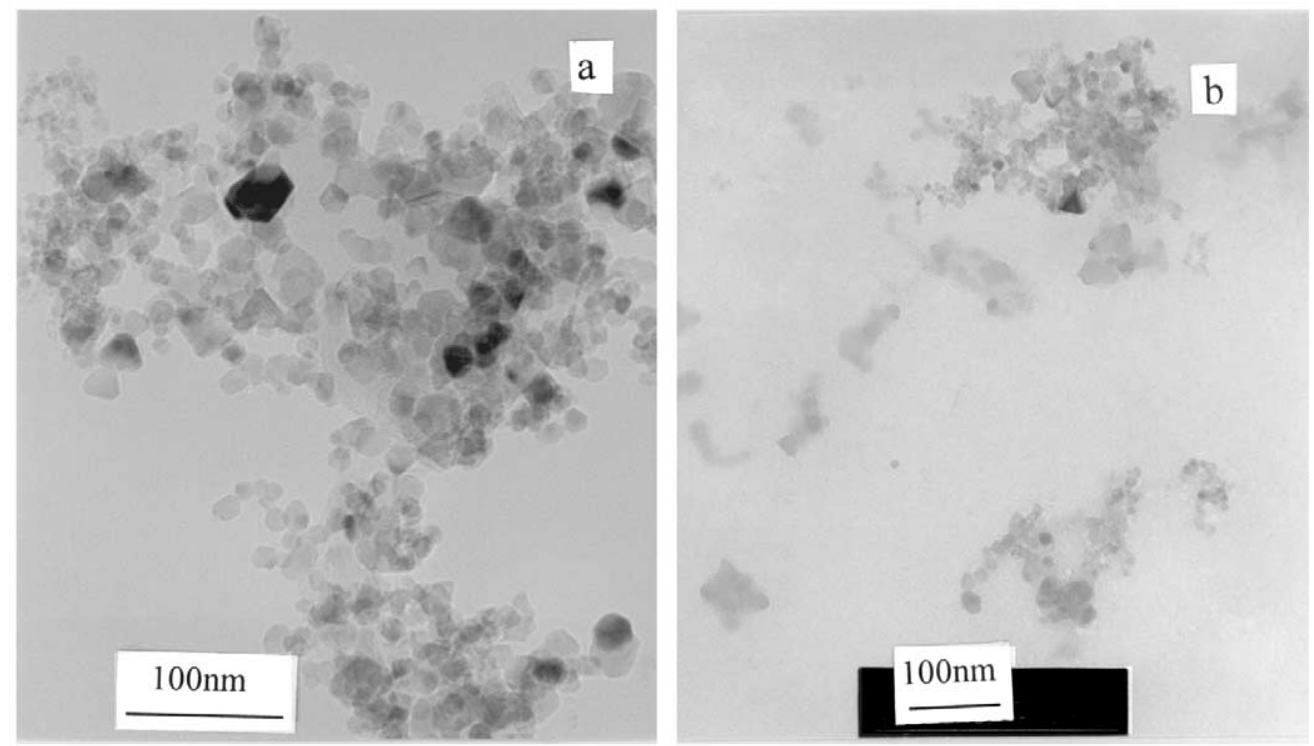

Fig. 7. TEM photographs of the $\mathrm{SiC}$ nanopowders produced in $\mathrm{Ar}$ (a) and $\mathrm{N}_{2}$ (b).

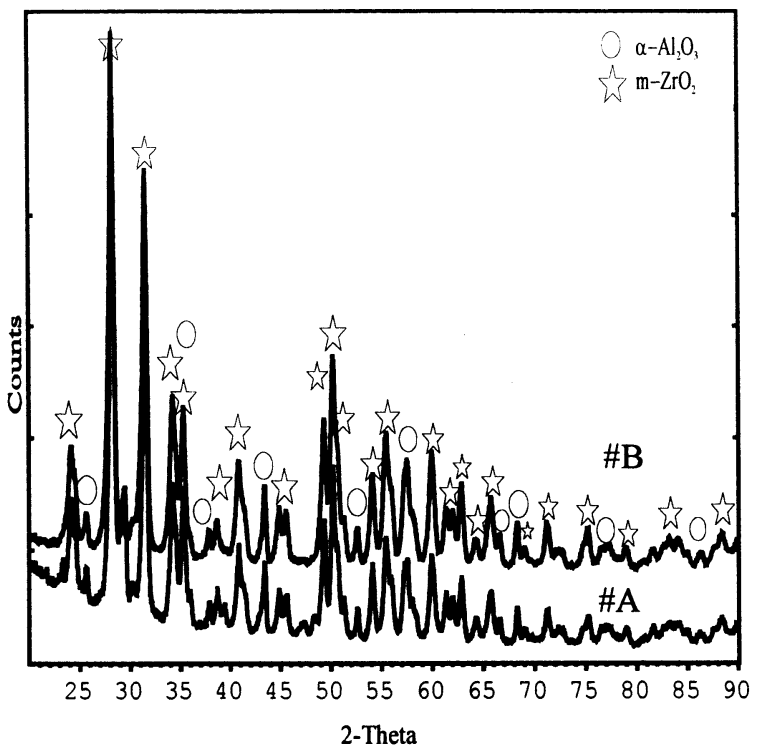

Fig. 8. XRD diagrams of samples \#A and \#B used for laser evaporation.

$d=\frac{k \lambda}{\beta \cos \theta}$,

where $d$ is the crystalline size, $k$ is a constant number ( $k=0.9), \lambda$ is the X-ray wavelength (1.5406 $\AA$ ), $\theta$ is half the diffraction angle for the reflection measured. $\beta$ is the full width at half maximum (FWHM) for the reflection measured.

Fig. 11 gives TEM micrographs of NS1 and NS2. It shows that the particles are nearly spherical and the powders have little aggregation. Some particles embedded in a glass matrix were found. Particles in NS1 and NS2 both obey lognormal distributions as shown in

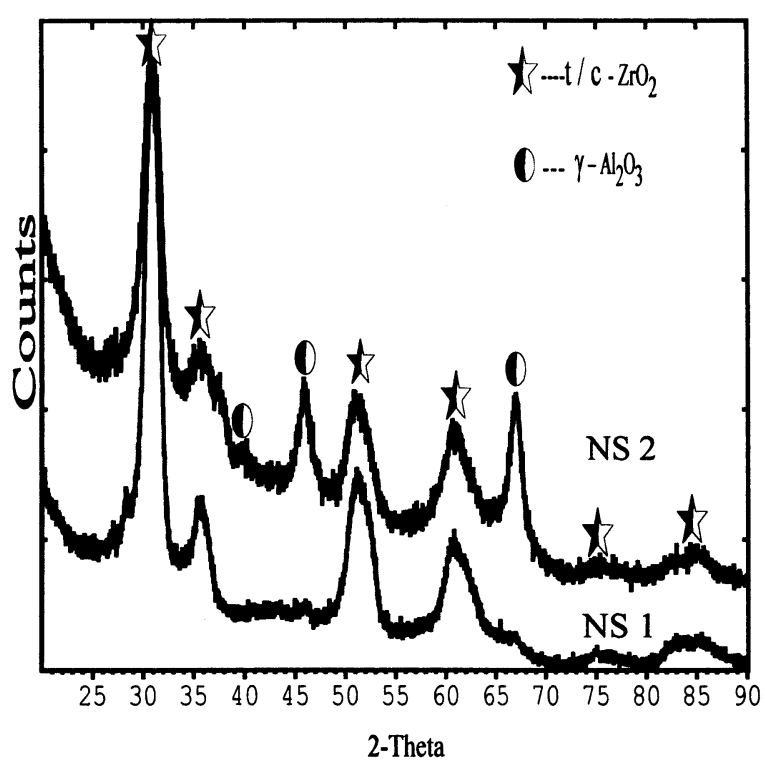

Fig. 9. XRD diagrams of NS1 and NS2.

Fig. 12. NS1 has a medium diameter of $8.3 \mathrm{~nm}$ with a geometric standard deviation of 1.51, and NS2 has a medium diameter of $9.9 \mathrm{~nm}$ with a geometric standard deviation of 1.42, respectively. HRTEM image in Fig. 13 shows that almost all particles are single crystal. That is, the crystalline size calculated from Scherrer formula should be nearly equal to the corresponding medium particle size measured from TEM. However, our results indicate that the calculated crystalline sizes are far smaller than the measured medium particle sizes. The difference originates from the instrumental effects [29] and microstrain effects in nanoparticles [30]. The particle marked as A in Fig. 13 shows a core-shell structure, where a single crystal of alumina-zirconia 


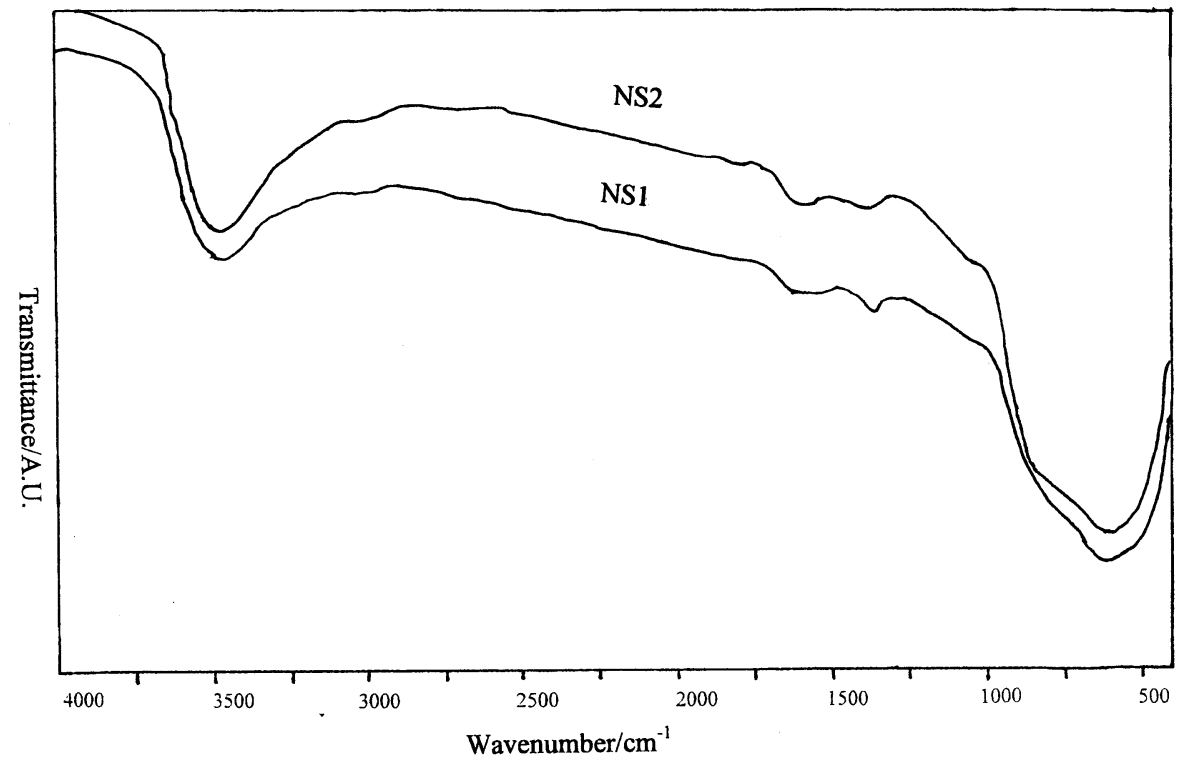

Fig. 10. IR absorption spectra of NS1 and NS2.

solid solution was embedded in a melting aluminazirconia matrix.

\section{Discussion}

\subsection{Particle morphology, agglomeration, and size distribution}

TEM observation shows that nanoparticles smaller than a critical size are spherical and have a strong agglomeration. The critical diameter is about $20 \mathrm{~nm}$, as suggested by Granqvist and Buhrman [5], while larger particles display growth habit and have little agglomeration as shown in Fig. 3(b) and in Fig. 7(a). Other TEM observations also show similar results $[5,26]$. Van der Waals force of attraction among particles increases with decreasing particle size, so smaller particles agglomerate more strongly. Powders prepared by laser ablation have little hard agglomeration, i.e. particle sintering as observed in our previous research [31]. Lognormal size distributions are obeyed in our powders. This is consistent with Ref. [5], where the lognormal distribution function was used to describe the size distribution of ultrafine metal particles produced by evaporation from a temperature-regulated oven containing a reduced atmosphere of an inert gas. Refs. [32,33] reported that metal nanopowders generated by sputtering or by plasma-discharge all obey lognormal size distributions. Thus it is rational to infer that nanoparticles produced by vapor-condensation methods obey lognormal size distributions, regardless of evaporated
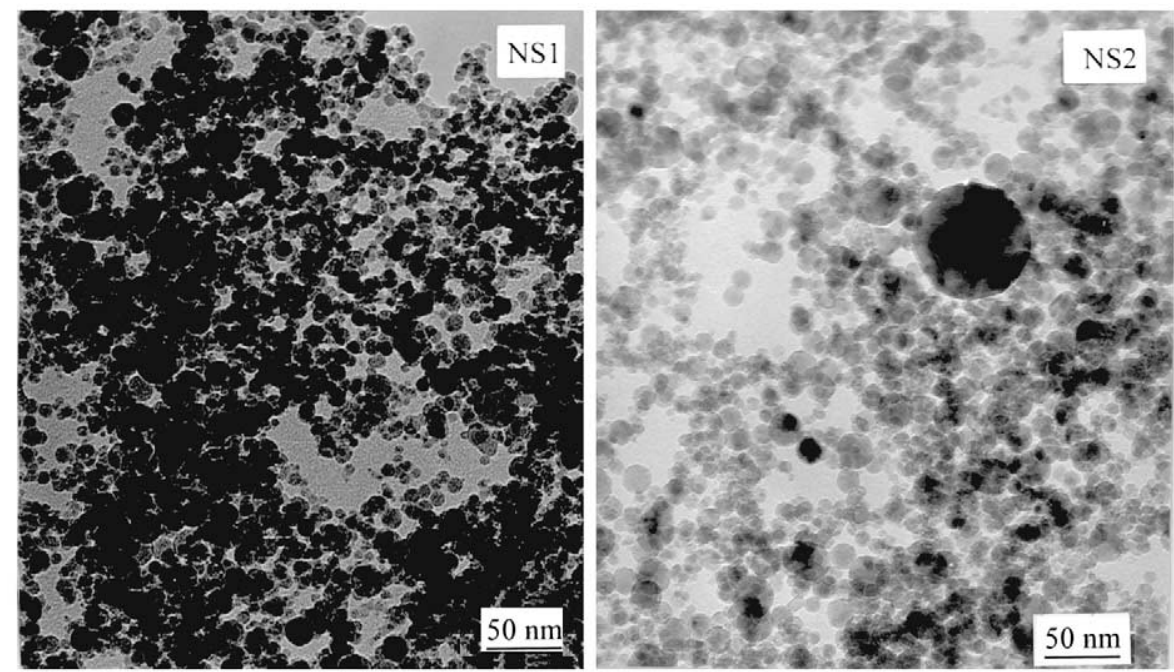

Fig. 11. TEM micrographs of NS1 and NS2. 
X.C. Yang et al. / Materials Science and Engineering B95 (2002) 299-307

305
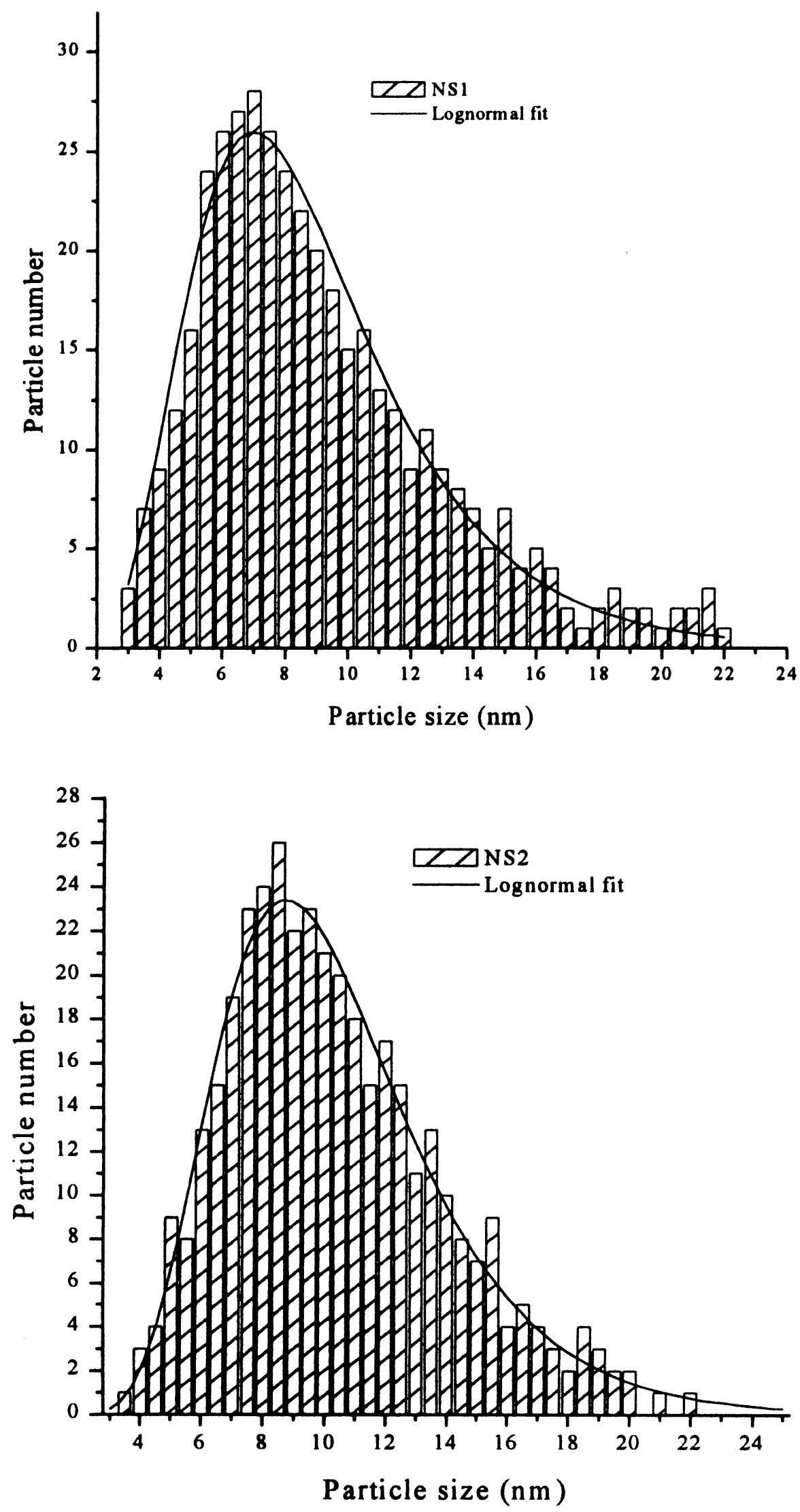

Fig. 12. Size distributions of nanoparticles in NS1 and NS2. 


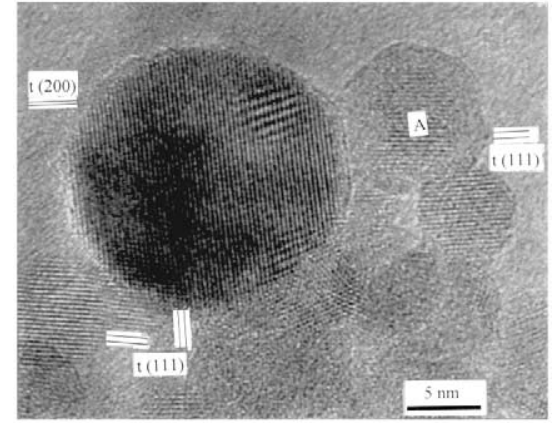

Fig. 13. HRTEM image of nanoparticles in NS1.

techniques used and particles growth processes involved. The origin of the lognormal distribution were further explained by Granqvist' research group [34]. It is very interesting that copper oxide particles synthesized in $\mathrm{Ar}$ atmosphere are needle-like, however, copper oxide particles produced in air are nearly spherical, indicating an important effect of atmosphere on particle morphologies.

\subsection{Phase transformation}

Inorganic materials evaporated by high-intensity laser beams transform into gas phases. Afterwards, the gas phases condense into solid states (clusters or nanoparticles) again due to high supersaturation. The condensed phases usually exist in the form of the corresponding low-temperature phases. For example, the condensed phase is cubic $\mathrm{SiC}$ after laser evaporating $\alpha$-SiC. In NS1 and NS2, however, zirconia and alumina are in metastable phases. This can be explained by the fine crystallite size, high solid solution content and high cooling rate. Garvie et al. reported that the $\mathrm{m}-\mathrm{t}$ transformation temperature of pure $\mathrm{ZrO}_{2}$ decreases with decreasing crystalline size. When it decreases to $\sim 30 \mathrm{~nm}, \mathrm{t}-\mathrm{ZrO}_{2}$ can exist at room temperature [35]. Luo and Stevens reported that the crystalline size of the $3 \mathrm{Y}$-TZP particles must be $>10 \mathrm{~nm}$ to retain tetragonal structure, smaller crystals would exist in cubic structure [36]. Previous investigations also showed that when doped with 2-7 $\mathrm{mol} \% \mathrm{Y}_{2} \mathrm{O}_{3}, \mathrm{ZrO}_{2}$ exhibits tetragonal structure, when doped with 7-12 $\mathrm{mol} \% \mathrm{Y}_{2} \mathrm{O}_{3}, \mathrm{ZrO}_{2}$ exhibits cubic structure [37]. Thus the $\mathrm{ZrO}_{2}$ in our powders should exist in the form of the cubic structure due to the small crystalline size $(<10 \mathrm{~nm})$ and the high solid solution content $(28 \mathrm{~mol} \%)$.

\subsection{Change of composition}

Transition metal oxides often decompose at hightemperature. For example, $\mathrm{CuO}$ decomposed completely into $\mathrm{Cu}_{2} \mathrm{O}$ and metallic $\mathrm{Cu}$ in argon atmosphere. In air atmosphere, however, the high oxygen partial pressure retarded the decomposition of copper oxide. Thus the copper oxide powder produced by laser ablation is a multi-phase mixture. Compositions of the mixture can be adjusted by controlling atmospheres.

Some non-oxides are easily oxidized if oxygen exists in the reactor. For example, $\mathrm{SiC}$ was partially oxidized into $\mathrm{SiO}_{2}$ in our experiments. The existence of $\mathrm{SiO}_{2}$ is harmful to $\mathrm{SiC}$ high-temperature properties. There are two types of $\mathrm{SiO}_{2}$ in $\mathrm{SiC}$ powders produced by laser ablation: crystalline and amorphous $\mathrm{SiO}_{2}$. Their forming mechanisms are as follows:

$\mathrm{SiC}(\mathrm{s}) \rightarrow \mathrm{SiC}(\mathrm{g})$

$\mathrm{SiC}(\mathrm{g})+\mathrm{O}_{2} \rightarrow \mathrm{SiO}_{2}(\mathrm{~g})+\mathrm{CO}_{2}$

$\mathrm{SiC}(\mathrm{g}) \rightarrow \mathrm{SiC}$ (nuclei) $\rightarrow \mathrm{SiC}$ (nanoparticles)

$\mathrm{SiO}_{2}(\mathrm{~g}) \rightarrow \mathrm{SiO}_{2}$ (nuclei) $\rightarrow \mathrm{SiO}_{2}$ (crystalline)

$\mathrm{SiC}$ (solid) $+\mathrm{O}_{2} \rightarrow \mathrm{SiO}_{2}$ (amorphous) $+\mathrm{CO}_{2}$

In $\mathrm{N}_{2}$ atmosphere, the expected $\mathrm{SiC}-\mathrm{Si}_{3} \mathrm{~N}_{4}$ composite powder was not obtained because the reaction of $\mathrm{SiC}$ and $\mathrm{O}_{2}$ impurity as mentioned above is much more active than that of $\mathrm{SiC}$ and $\mathrm{N}_{2}$. It will be possible to obtain the composite powder by increasing the purity of $\mathrm{N}_{2}$ or using the active gas ammonia instead of the inert gas $\mathrm{N}_{2}$.

\subsection{Forming mechanism of nanoparticles}

High-energy laser can evaporate almost all inorganic materials during laser ablation. The evaporated materials condense into nanoparticles by collision and coalescence or nucleation and growth.

Fig. 14 shows a simple model of particle formation. When the laser beam ablates the target, a part of its

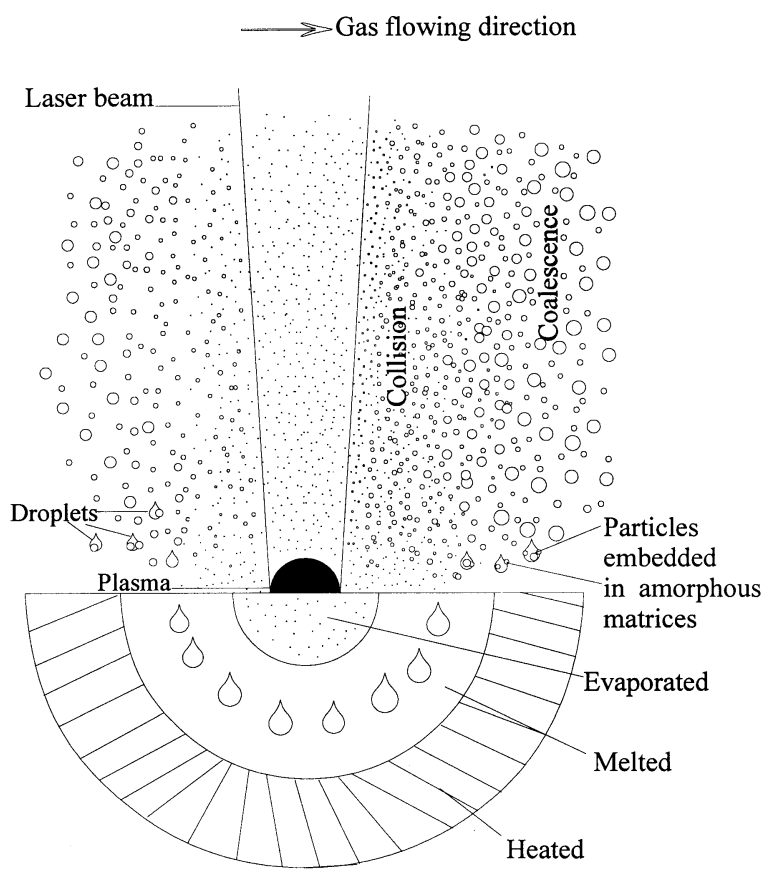

Fig. 14. A simple model of particle formation. 
energy is absorbed due to interactions of the laser photons with the electrons of the target, and plasma creates at the surface leading to a nearly complete absorption of the incident laser energy [38]. The absorbed energy induces a temperature gradient in the target, which depends on the heat conductivity of the target and the laser intensity. Then the target is heated, melted and evaporated. The evaporated material expands like a small explosion and forces the melted material out of the crater with a high velocity. The quick solidification of the melted material keeps it amorphous. When the melted material leaves the crater and solidifies, some nanoparticles condensed from the evaporated phase penetrate into the melted phase due to the collision between them. According to the model, we can explain Fig. 11, where particles embedded in glass matrices have been observed. The core-shell structure shown in Fig. 13 formed when a single particle was embedded in an amorphous matrix.

\section{Conclusions}

Nanopowders such as copper oxide, silicon carbide and $\mathrm{Al}_{2} \mathrm{O}_{3}-\mathrm{ZrO}_{2}$ were synthesized by laser ablation under different atmospheres. Nanoparticles smaller than $20 \mathrm{~nm}$ are spherical and have a strong agglomeration, while larger particles display the growth habit and have little agglomeration. Lognormal distribution is a universal rule for nanoparticles produced by vapor condensation. Atmosphere has an important effect not only on particle morphologies but also on particle compositions. The solid solution limit of $\mathrm{Al}_{2} \mathrm{O}_{3}$ in $\mathrm{ZrO}_{2}$ produced in air $(28 \mathrm{~mol} \%)$ is a little smaller than that produced in $\mathrm{Ar}(33 \mathrm{~mol} \%)$. The $\mathrm{ZrO}_{2}$ in our powder is suspected to be the cubic structure due to the small crystallite size $(<10 \mathrm{~nm})$ and the high solid solution content $(28 \mathrm{~mol} \%)$. A model has been proposed to explain the forming mechanism of nanoparticles, especially the nanoparticles embedded in amorphous matrices.

\section{Acknowledgements}

The author, XCY, is grateful to Dr J. Naser and E. Meyer for their technical help. This research was funded by Deutsche Forschungsgemeinschaft.

\section{References}

[1] Hari Singh Nalwa (Ed.), Handbook of Nanostructured Materials and Nanotechnology, vol. 1-4, Academic Press, San Diego, 1999.
[2] R.W. Siegel, Mater. Sci. Eng. B19 (1993) 37.

[3] J. Karch, R. Birringer, H. Gleiter, Nature 330 (1987) 556.

[4] H. Gleiter, Prog. Mater. Sci. 33 (1991) 223.

[5] C.G. Granqvist, R.A. Buhrman, J. Appl. Phys. 47 (1976) 2200.

[6] X.C. Yang, Z.S. Ding, J. Mater. Res. 15 (2000) 2140.

[7] V.V. Srdic, M. Winterer, A. Moeller, G. Miehe, H. Hahn, J. Am. Ceram. Soc. 84 (2001) 2771.

[8] J. Dutta, H. Hofmann, C. Hollenstein, H. Hofmeister, in: Janos H. Fendler (Ed.), Nanoparticles and Nanostructured Films, Wiley-VCH, Weinheim, 1998, p. 173.

[9] R. Fantoni, E. Borsella, S. Piccirillo, R. Ceccato, S. Enzo, J. Mater. Res. 5 (1990) 143.

[10] N. Claussen, G. Lindemann, G. Petzow, Ceram. Int. 9 (1983) 83.

[11] M.L. Balmer, F.F. Lange, V. Jayram, C.G. Levi, J. Am. Ceram. Soc. 78 (1995) 1489.

[12] G.D. Ulrich, Chem. Eng. News, August 6 (1984) 22.

[13] S. Vemury, S.E. Pratsinis, L. Kibbey, J. Mater. Res. 12 (1997) 1031.

[14] S.H. Ehrman, S.K. Friedlander, M.R. Zachariah, J. Aerosol Sci. 29 (1998) 687.

[15] G.F. Gaertner, H. Lydtin, Nanostruc. Mater. 4 (1994) 559.

[16] W. Riehemann, in: K.E. Gonsalves et al. (Eds.), SurfaceControlled Nanoscale Materials for High-Added-Value Applications, MRS Symp. Proc., vol. 501, 1998, p. 95.

[17] M.F. Becker, Nanostruct. Mater. 10 (1998) 853.

[18] T. Kosugi, S. Kaneko, J. Am. Ceram. Soc. 81 (1998) 3117.

[19] R. Brutsch, Thin solid Films 126 (1985) 313.

[20] J.A. Powell, L.G. Matus, Recent developments in SiC (USA), in: L. Harris, C.Y.-W. Yang (Eds.), Springer Proceedings in Physics Amorphous and Crystalline Silicon Carbide, vol. 34, SpringerVerlag, Berlin, FRG, 1989, pp. 2-11.

[21] E.C. Subbarao, in: A.H. Heuer, L.W. Hobbs (Eds.), Science and Technology of Zirconia, Ser. Adv. Ceramics, vol. 3 (Chapter 1), American Ceramic Society, Columbus, OH, (1981) 1-24.

[22] J. Cai, Y.S. Raptis, E. Anastassakis, Phys. Rev. B51 (1995) 201.

[23] C. Itoh, T. Suzuki, N. Itoh, Phys. Rev. B41 (1990) 3794.

[24] E. Sominska, B. Cina, R. Chaim, A. Gedanken, J. Am. Ceram. Soc. 83 (2000) 89.

[25] Z. Qian, J.L. Shi, Nanostruct. Mater. 10 (1998) 235.

[26] X.C. Yang, W. Riehemannn, Scripta Mater. 45 (2001) 435.

[27] M. Swain, in: R.W. Cahn, P. Haasen, E.J. Kramer (Eds.), Materials Science and Technology VCH, Weinheim, vol. 11, 1993, p. 103.

[28] P. Scherrer, Nachr. Ges. Wiss. Goettingen, 1918, pp. 98-100.

[29] H.P. Klug, L.E. Alexander, X-ray Diffraction Procedures for Polycrystalline and Amorphous Materials, Wiley, New York, 1974, p. 662.

[30] R.L. Snyder, X-ray diffraction, in: E. Lifshin (Ed.), X-ray Characterization of Materials, Wiley-VCH, Weinheim, 1999, p. 37.

[31] X.C. Yang, G.R. Han, P.Y. Du, Z.S. Ding, J. Chin. Ceram. Soc. 25 (1997) 332.

[32] V. Haas, R. Birringer, Nanostruct. Mater. 1 (1992) 491.

[33] A.C. Xenoulis, T. Tsakalakos, Nanostruct. Mater. 12 (1999) 311.

[34] J. Soderlund, L.B. Kiss, G.A. Niklasson, C.G. Granqvist, Phys. Rev. Lett. 80 (1998) 2386.

[35] R.C. Garvie, R.H.J. Hannik, R.T. Pascoe, Nature 258 (1975) 703.

[36] J. Luo, R. Stevens, J. Am. Ceram. Soc. 82 (1999) 1922.

[37] H.G. Scott, J. Mater. Sci. 10 (1975) 1527.

[38] W.M. Steen, Laser Material Processing, Springer-Verlag, London, 1991, p. 43. 